\title{
REDUÇÃO DO DESGASTE E DESPRENDIMENTO DE PINOS POR ESCORREGAMENTO EM PRENSA DE ROLOS*
}

Bruno Miranda Ribeiro ${ }^{1}$ Gilvandro Bueno²

\section{Resumo}

Foi verificado que em uma das prensas de rolos (HPGR, High Pressure Griding Rolls), das usinas de pelotização de Tubarão, estava ocorrendo escorregamento do minério entre os pinos (studs) ocasionando um desgaste excessivo no rolo e desprendimento dos pinos. Este fato levou ao desenvolvimento de uma solução para eliminar o problema através da utilização de um produto que contivesse as características necessárias para conter o desgaste e prolongar a vida útil do rolo, sem comprometer a performance da prensa. As etapas para solução do problema passou por uma definição da escolha do produto, preparação da superfície do rolo e método de aplicação. Após implantada a solução, foram comparados os resultados antes e depois da aplicação do produto. Os resultados mostraram que o objetivo foi alcançado quanto a retenção dos pinos, controle do desgaste e manutenção da performance de processo desta prensa.

Palavras-chave: Prensa de rolos; Desgaste; Performance; Escorregamento.

\section{WEAR REDUCTION AND STUDS DETACHMENT BY SLIPPING ON ROLLER PRESS}

\begin{abstract}
It was checked in one of the roller press (HPGR, High Pressure Griding Rolls) in Tubarão pellet plants, was occurring iron ore slipping between pins (studs) causing excessive wear on the roll and studs detachment. This fact stated the development of a solution for eliminating the problem by using a product that contains the necessary features to contain the wear and extend the life of the roll, without compromising the performance of the press. The steps for problem solution underwent a definition of product choice, rolls surface preparation and application method. After deployed the solution, the results were compared before and after the application of the product. The results showed that the objective was achieved on the retention pins, wear control process and the maintenance of this performance press.
\end{abstract}

Keywords: High pressure griding rolls; Wear; Performance; Slipping.

1 Engenheiro Mecânico, Engenheiro de Manutenção Pleno, Pelotização, Vale, Vitória, ES, Brasil

2 Engenheiro Metalurgista, Engenheiro de Processo Máster, Pelotização, Vale, Vitória, ES, Brasil. 


\section{INTRODUÇÃO}

No processo de aglomeração para formação de pelotas, forças de adesões capilares são importantes mecanismos para garantir uma boa resistência da pelota crua. Para maximizar estas forças é necessário garantir entre outros fatores uma superfície específica adequada do minério de ferro. No processo de pelotização a elevação da superfície especifica do minério é gerada através dos processos de moagem e prensagem utilizando-se prensas de rolos.

As prensas de rolos (HPGR, High Pressure Griding Rolls) são equipamentos de cominuição que consistem em um par de rolos composto de pinos cravados (studs) girando em sentidos opostos, montados em um quadro rígido. Um rolo gira sobre um eixo fixo no quadro, enquanto o outro eixo se desloca sobre guias, sendo posicionado por cilindros hidráulicos. A alimentação é introduzida na abertura entre rolos, onde a diminuição de tamanho ocorre pelo efeito da cominuição interparticular. A figura 1 mostra uma representação esquemática do funcionamento da prensa de rolos.

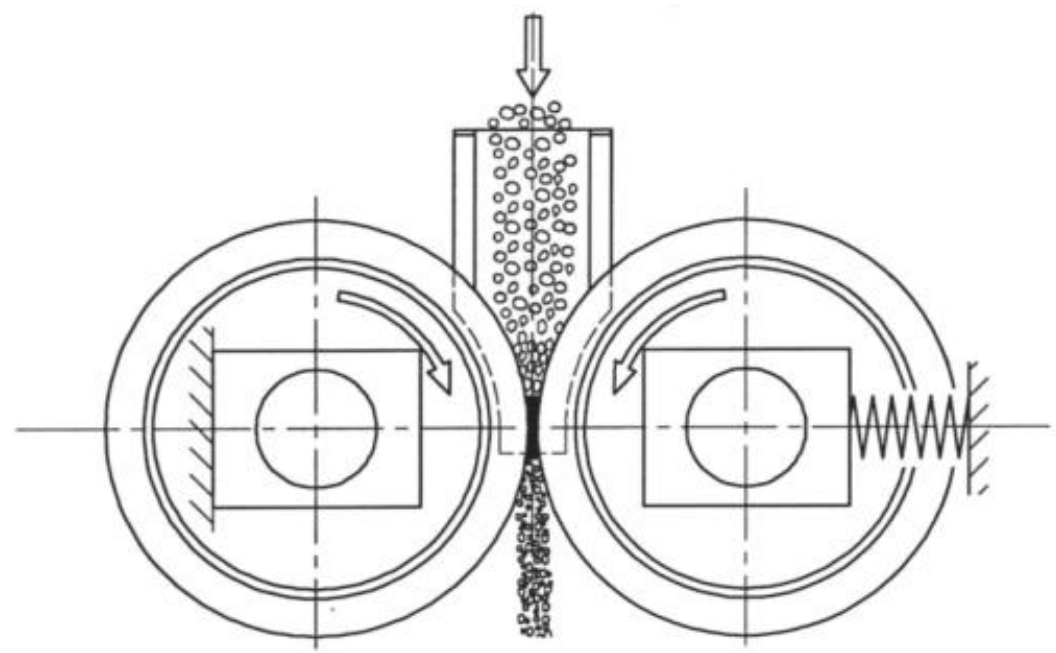

Figura 1. Esquema da prensa de rolos

Em geral, a motivação para a utilização de prensas de rolos está relacionada à sua maior eficiência energética, se comparada com a eficiência dos moinhos convencionais, pois, nas prensas de rolos ocorre lenta aplicação de carga sobre as partículas, causando colapso estrutural dos grãos, de modo que a energia perdida em calor e ruído é minimizada. Na figura 2 é apresentado o princípio de cominuição da prensa de rolos.
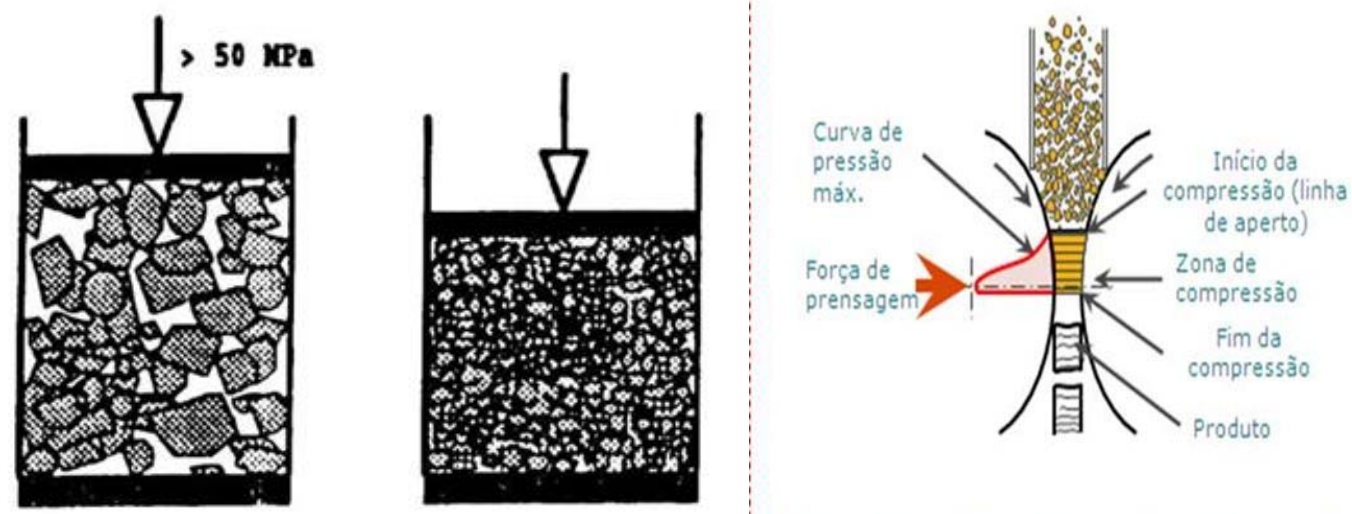

Figura 2. Princípio de cominuição da prensa de rolos 
$45^{\circ}$ Redução

$16^{\circ}$ Minério de Ferro

$3^{\circ}$ Aglomeração

ISSN 2176-3135

Alguns fatores como pressão excessiva, elevação da umidade e alimentação deficiente podem fazer com que haja um escorregamento do minério a ser prensado tendendo este a fluir e ser extrudado entre os pinos causando desgaste prematuro e acentuado na bandagem do rolo. Este fenômeno é explicado na literatura, através da comparação de imagens foi constatado que o mesmo efeito estava ocorrendo em uma das prensas da Usina de Pelotização em Tubarão, Vitória - ES. A presença deste fenômeno acarreta em queda de pinos dos rolos, com a queda de pinos temos um desgaste muito acentuado na bandagem, provocando buracos nos rolos, sendo necessário o reparo ou até mesmo a substituição. A figura 3 mostra o fenômeno apresentado na literatura, a figura 4 o que foi verificado em campo e a figura 5 os buracos nos rolos causados devido a presença desse fenômeno.

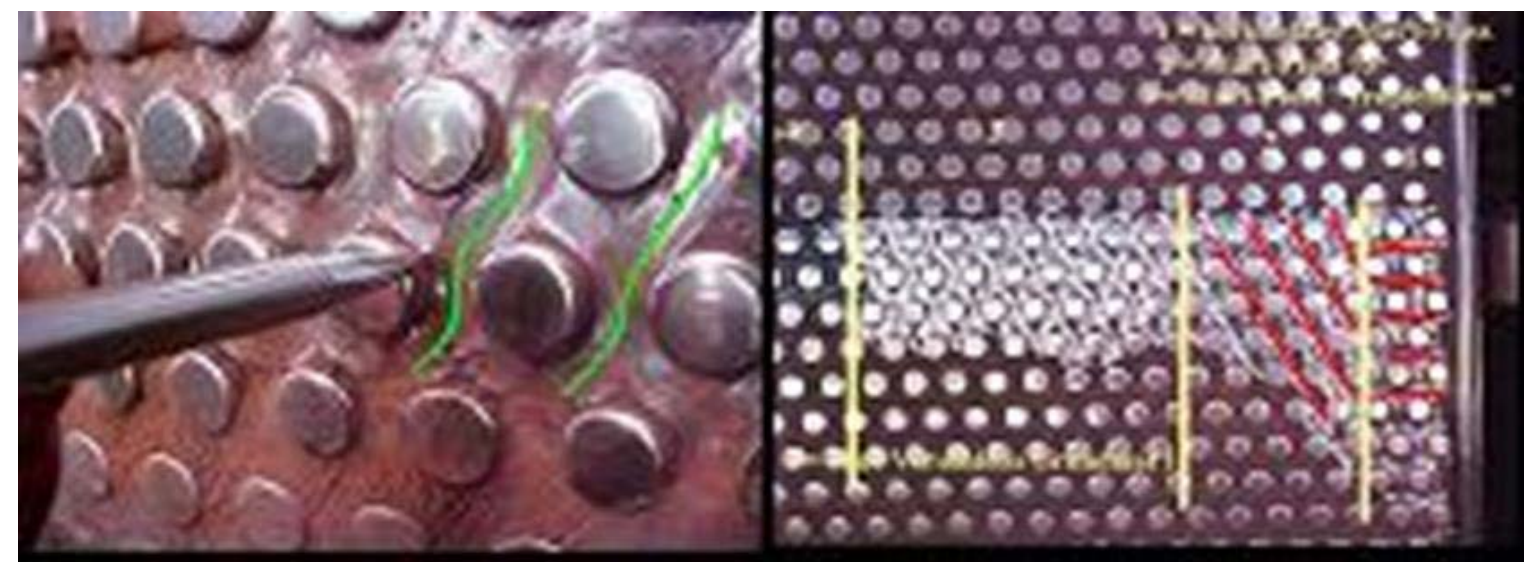

Figura 3. Apresentação do fenômeno retirado da literatura
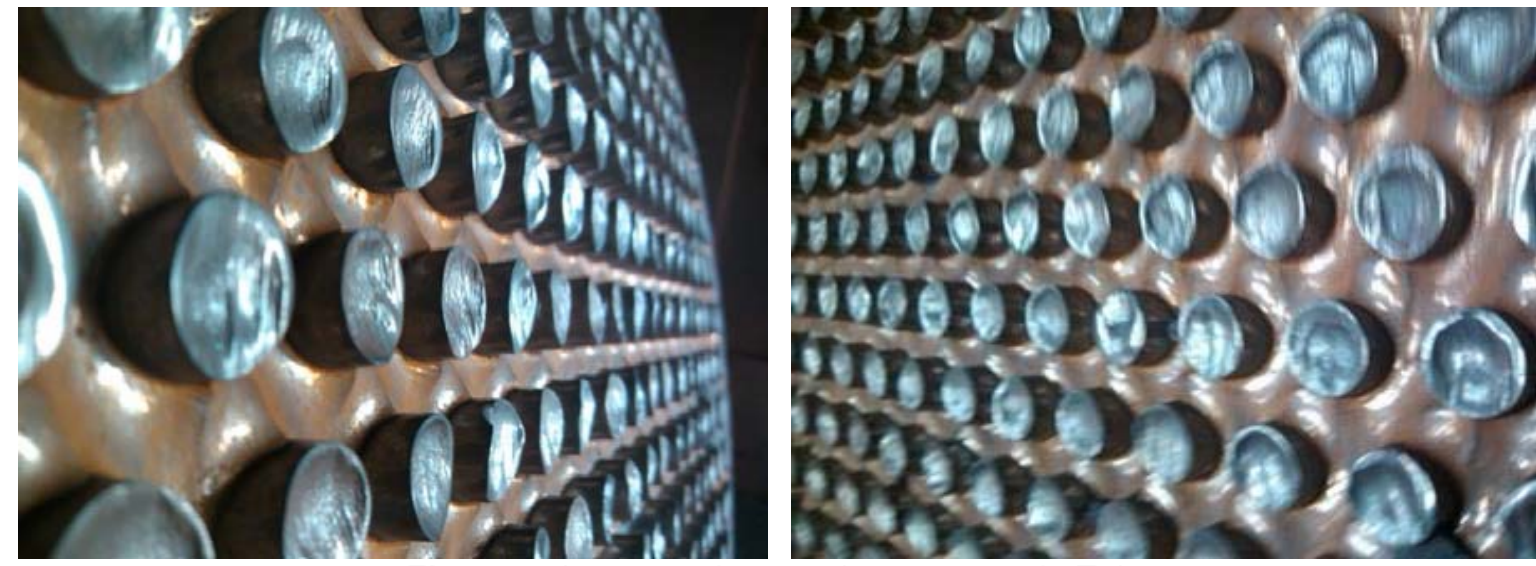

Figura 4. Imagens de uma das prensas de Tubarão
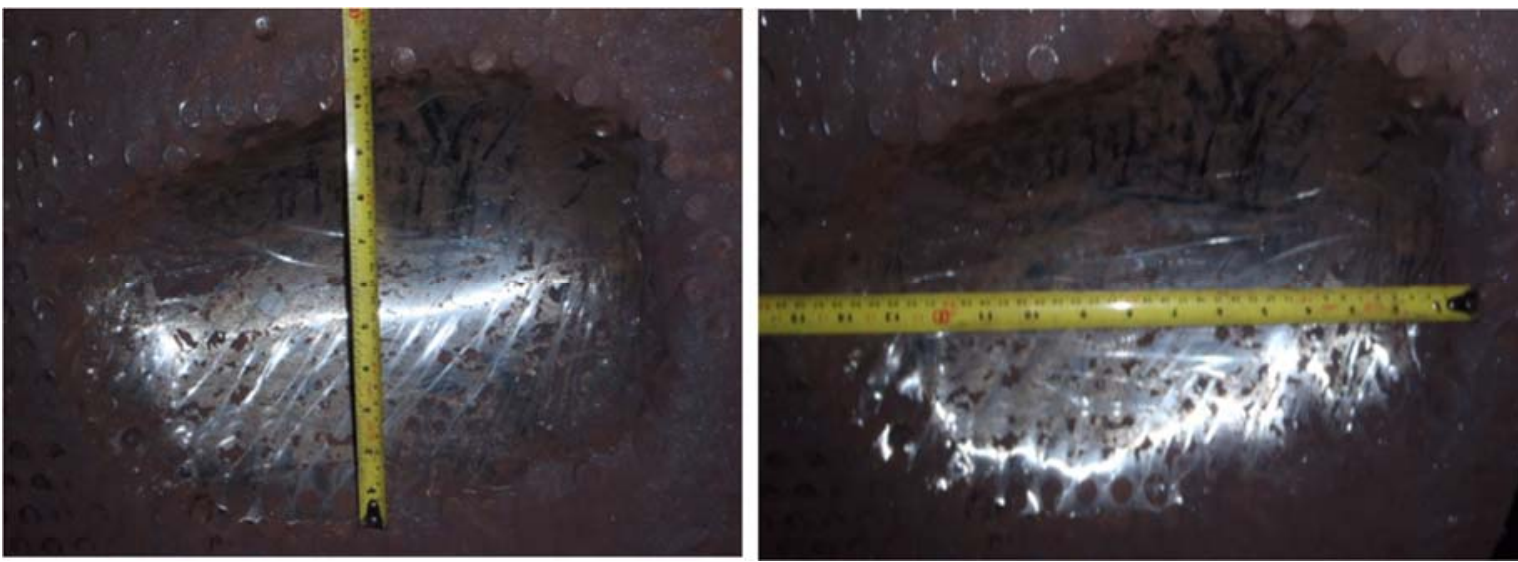

Figura 5. Imagens de uma das prensas de Tubarão 
A verificação deste fenômeno motivou a equipe de manutenção a buscar uma alternativa que prolongasse a vida útil dos rolos que estava sendo comprometida pelo escorregamento do minério, foi então que se optou por aplicar uma Resina Cerâmica de elevada resistência ao desgaste e compressão, que fosse capaz de aderir à superfície do rolo entre os pinos. Foi necessária também uma verificação de desempenho da prensa após a aplicação desta resina, esta verificação foi realizada pela equipe de processo avaliando alguns parâmetros chaves de modo a concluir se esta seria uma boa prática para prolongar a vida útil do rolo sem que houvesse perda de performance da prensa.

\section{MATERIAIS E MÉTODOS}

Para combater os efeitos do fenômeno já mencionado e evitar a queda de pinos e posterior avaria dos rolos, foram realizados levantamentos de campo e estudos. Para considerarmos um produto efetivo, necessitaríamos que o mesmo tivesse principalmente 4 características:

1. Alta resistência a abrasão para não haver o desgaste prematuro do produto;

2. Alta resistência a compressão para que não houvesse a quebra do produto;

3. Grande aderência na bandagem dos rolos para não haver desprendimento do produto aplicado;

4. Não interferir na performance da prensa após aplicação.

\subsection{Análise da Compressão Exercida nos Rolos}

Para saber qual compressão o produto teria que resistir, era necessário antes saber qual a maior pressão exercida nos rolos. Foi feito uma filmagem termográfica, onde identificamos que a região onde tem o maior trabalho é a região central dos rolos conforme mostra a figura 6 . Para saber a pressão aplicada nos rolos foi consultado o fabricante onde o mesmo informou a pressão máxima ser de $300 \mathrm{Mpa}$ quando a prensa trabalha com o hidráulico em sua pressão máxima, como a pressão do hidráulico de trabalho atual da prensa é $1 / 3$ da pressão máxima, chegamos a conclusão que o produto teria que resistir a uma compressão superior a 100Mpa.

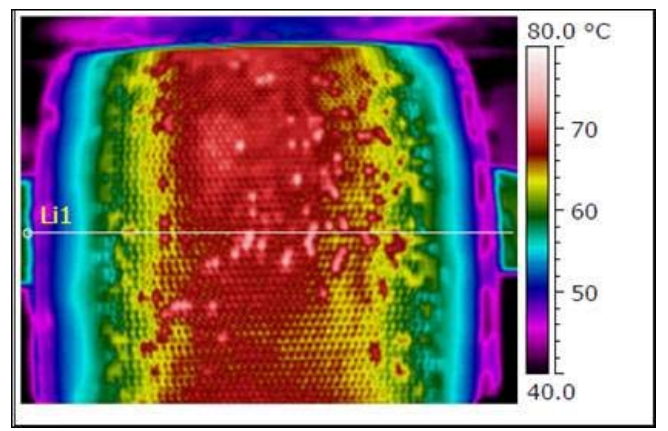

Figura 6. Análise termográfica do rolo

\subsection{Análise de Diferentes Produtos}

Sabendo qual a compressão necessária que o material teria que resistir foi feito contato com diferentes fabricantes, para que nos enviasse a folha de dados (datasheet) de seus produtos recomendados para tal aplicação. Após análise dos dados, decidimos realizar o teste com um produto de uma aplicação mais simples e menor custo. 
Tabela 1. Dados técnicos do produto escolhido

\begin{tabular}{|c|c|c|c|}
\hline \multicolumn{4}{|l|}{ Technical Data } \\
\hline Composition & \multicolumn{3}{|c|}{ A modified epoxy resin reacted with an aliphatic amine curing agent } \\
\hline Reinforcement & \multicolumn{3}{|c|}{ Proprietary blend of high purity $\mathrm{Al}_{2} \mathrm{O}_{3}$ and $\mathrm{SiC}$, pretreated with polymeric coupling agent } \\
\hline Cured Density & & $2.7 \mathrm{~g} / \mathrm{cc}$ & $168 \mathrm{lb} /$ cu.ft. \\
\hline Compressive Strength & (ASTM D 695) & $1125 \mathrm{~kg} / \mathrm{cm}^{2}$ (110.3 MPa) & $16,000 \mathrm{psi}$ \\
\hline Flexural Strength & (ASTM D 790) & $485 \mathrm{~kg} / \mathrm{cm}^{2}(47.6 \mathrm{MPa})$ & $6,900 \mathrm{psi}$ \\
\hline Tensile Adhesion & (ASTM D 4541) & $224.8 \mathrm{~kg} / \mathrm{cm}^{2}(22.1 \mathrm{MPa})$ & 3,200 psi \\
\hline Tensile Strength & (ASTM D 638) & $211 \mathrm{~kg} / \mathrm{cm}^{2}(20.7 \mathrm{MPa})$ & $3,000 \mathrm{psi}$ \\
\hline Impact Resistance (Reverse) & (ASTM D 2794) & $9.0 \mathrm{~N}-\mathrm{m}$ & 80 in-lbs. \\
\hline Shore D Durometer Hardness & (ASTM D 2240) & 89 & \\
\hline $\begin{array}{l}\text { Vertical Sag Resistance, } \\
\text { at } 21^{\circ} \mathrm{C}\left(70^{\circ} \mathrm{F}\right) \text { and } 6 \mathrm{~mm}\left(1 / 4^{*}\right)\end{array}$ & & No Sag & \\
\hline $\begin{array}{l}\text { Maximum Temperature } \\
\text { (Dependent on service) }\end{array}$ & $\begin{array}{l}\text { Wet Service } \\
\text { Dry Service }\end{array}$ & $\begin{array}{l}95^{\circ} \mathrm{C} \\
205^{\circ} \mathrm{C}\end{array}$ & $\begin{array}{l}203^{\circ} \mathrm{C} \\
400^{\circ} \mathrm{C}\end{array}$ \\
\hline Shelf life (unopened containers) & \multicolumn{3}{|c|}{2 years [stored between $10^{\circ} \mathrm{C}\left(50^{\circ} \mathrm{F}\right)$ and $32^{\circ} \mathrm{C}\left(90^{\circ} \mathrm{F}\right)$ in dry, covered facility] } \\
\hline
\end{tabular}

\subsection{Método de Aplicação}

A aplicação do produto consistiu basicamente de 4 etapas, sendo elas:

1. Demarcação do local a ser aplicado;

2. Preparação da superfície;

3. Mistura e aplicação de prime;

4. Mistura e aplicação do produto;

A resina é fornecida em um balde lacrado que consiste de 5 produtos, prime $A+B$, produto $A+B$ e cerâmica, são fornecidos pelo fabricante em suas devidas proporções para a aplicação.

\subsubsection{Demarcação do local a ser aplicado}

Os rolos da prensa em questão estavam apresentando desgaste prematuro apenas nas extremidades dos rolos, cada rolo possui um comprimento de $1550 \mathrm{~mm}$, porém o produto foi aplicado apenas em $500 \mathrm{~mm}$ de cada extremidade, conforme demarcação realizada que pode ser visto na figura 7 .

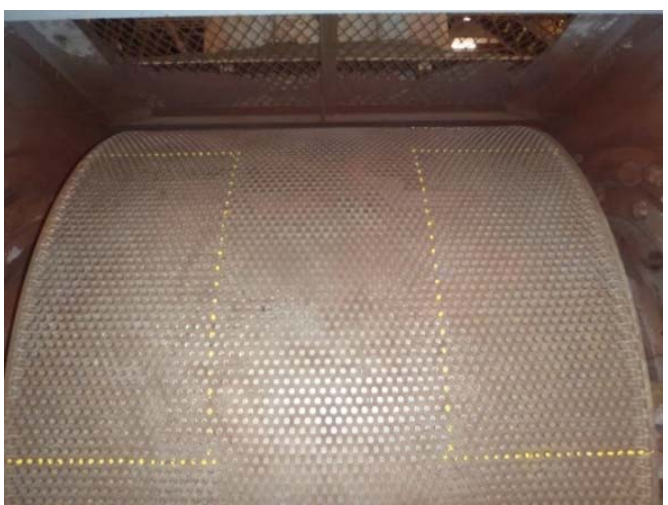

Figura 7. Demarcação da área

\subsubsection{Preparação da superfície}

Antes da aplicação do produto, foi necessária a preparação de superfície adequada, limpa e isenta de contaminantes e com uma rugosidade de perfil angular de 75 a 125 mícron. Para isso os rolos foram primeiramente lavados com jato de água e depois jateado com abrasivo, para atender a necessidade de rugosidade de aplicação. Na figura 8 visualizamos o rolo antes da preparação da superfície e na figura 9 , o rolo preparado para receber a resina. 


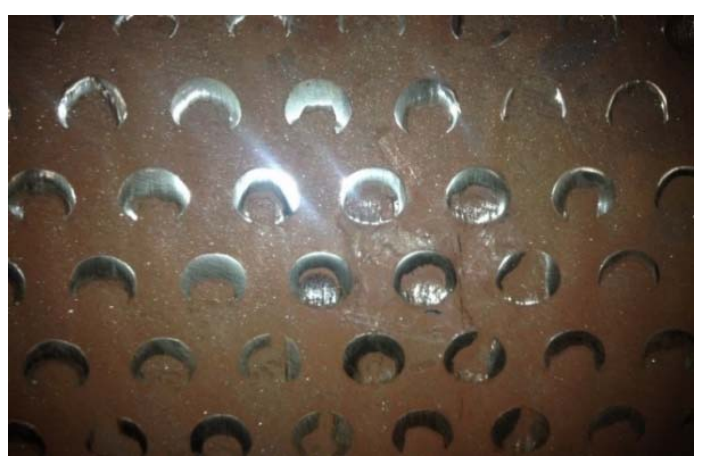

Figura 8. Rolo antes do jateamento

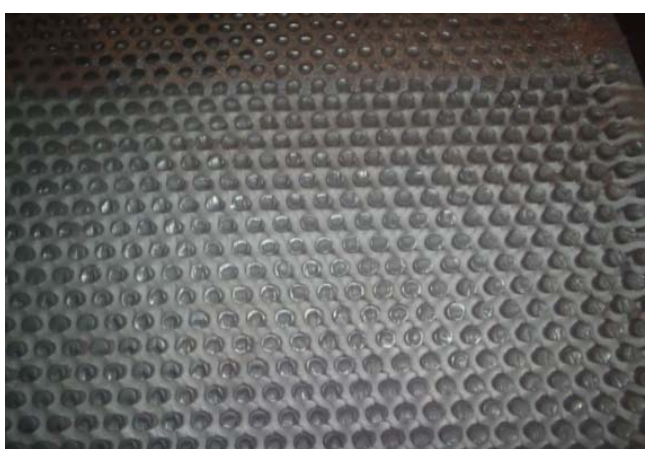

Figura 9. Rolo após jateamento

\subsubsection{Mistura e aplicação do prime}

Para permitir uma melhor aderência da resina cerâmica a ser aplicada, primeiramente foi aplicado um prime na superfície do rolo. O prime é um produto bicomponente, deve-se misturar parte A mais a parte B de forma homogênea e aplicar sobre a área a ser revestida com pincel ou rolo, com tempo limite de 15 minutos para começar a aplicar o revestimento, considerando uma temperatura de $32{ }^{\circ} \mathrm{C}$.

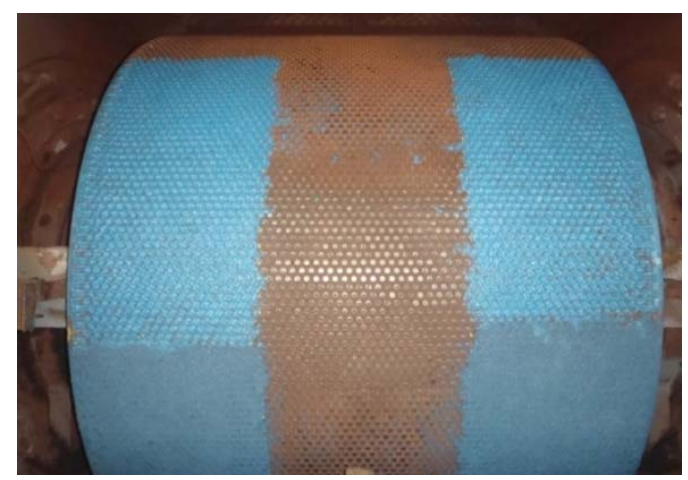

Figura 10. Rolo após aplicação do prime

\subsubsection{Mistura e aplicação do revestimento}

Após a aplicação do prime foi feita a mistura de 3 componentes, parte $A+B$ e a cerâmica, com o auxílio de um misturador elétrico, até que se obtivesse uma consistência uniforme. Depois foi aplicado de imediato, considerando o tempo de aplicação de 15 minutos para temperatura de $32^{\circ} \mathrm{C}$, espalhando e compactando a resina sobre a área aplicada, usando uma placa plástica e um martelo de borracha. Após a aplicação foi passada uma espátula no rolo para retirar o excesso do produto. Aguardado o tempo de cura de 3 horas e o equipamento liberado.

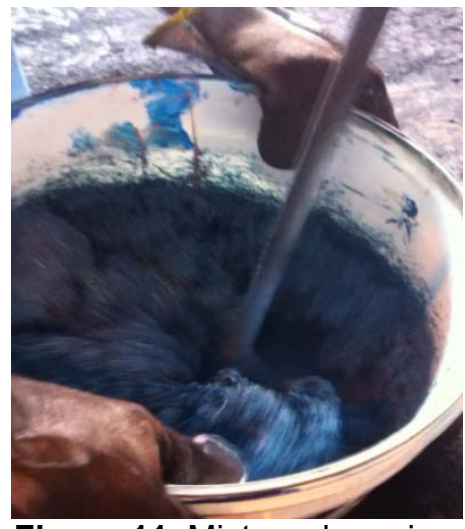

Figura 11. Mistura da resina

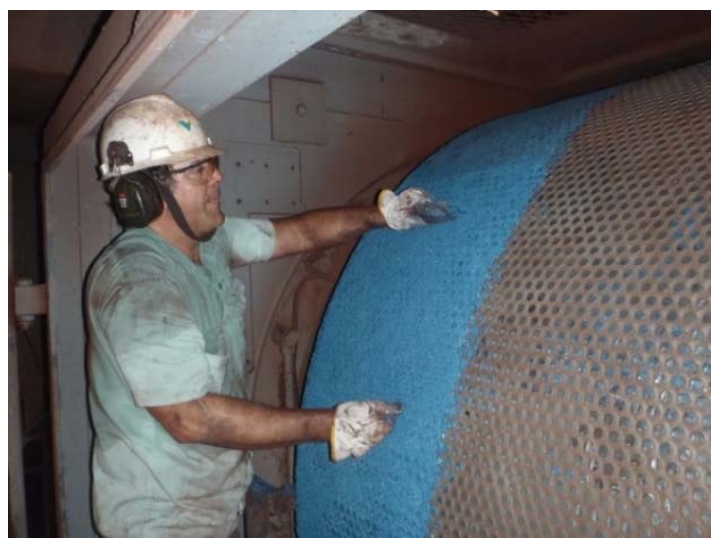

Figura 12. Superfície após aplicação do produto 


\section{RESULTADOS E DISCUSSÃO}

Após aplicação da resina cerâmica, houve a necessidade de verificar se produto aplicado teve o resultado esperado em relação a evitar o desgaste da bandagem dos rolos, desprendimento de pinos e se foi gerada alguma interferência na performance da prensa. Para esta análise, foi realizado um levantamento com dados de performance comparando-se os resultados antes e depois da aplicação da resina.

Para esta análise foi verificado os seguinte indicadores:

1. Geração de Superfície Específica $-\mathrm{cm}^{2} / \mathrm{g}$;

2. Consumo de Energia - kwh/t;

3. Torque - \%;

4. Pressão de trabalho - MPa;

5. Velocidade dos rolos - rpm;

6. Eficiência $-\mathrm{cm}^{2} / \mathrm{g} / \mathrm{kwh} / \mathrm{t}$;

Como informação complementar foi avaliado também a participação do minério de Itabira, por ter menor índice de moabilidade.

A aplicação da resina ocorreu entre os dias 27 a 31/10/2014.

O período de análise foi compreendido entre 07/08/2014 a 27/01/2015 sendo:

- Antes da Resina: 07/08 a 26/10/2014

- Depois da Resina: 01/11/2014 a 27/01/2015

\subsection{Desempenho da Resina Cerâmica Aplicada}

Após a aplicação da resina cerâmica foram feitas diversas inspeções para verificar se a resina teve o resultado esperado. Nas inspeções foram verificadas que a resina encontrava-se em bom estado sem quebras ou desprendimento desta da bandagem dos rolos e também foi constatado que não houveram desprendimento de pinos.

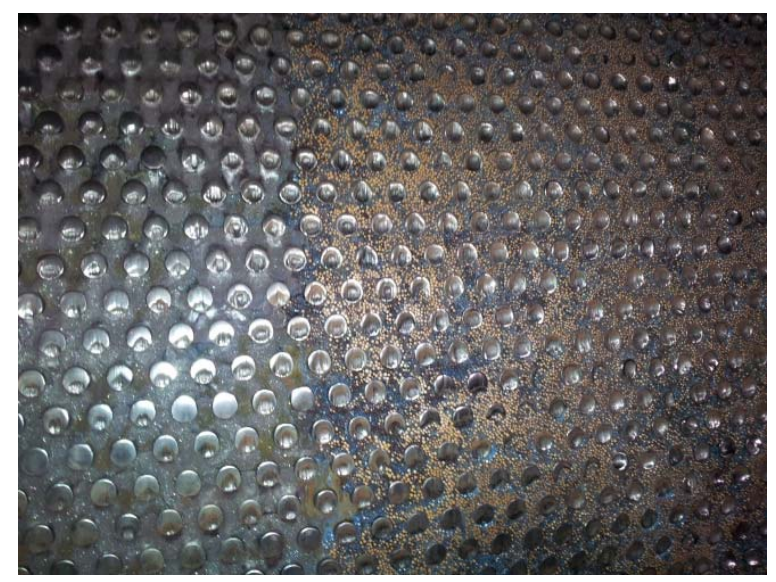

Figura 13. Inspeção após $240 \mathrm{~h}$ de funcionamento da prensa

\subsection{Pressão e Torque}

Após a aplicação da resina, a prensa continuou respondendo ao trabalho realizado, pois houve uma elevação do torque com elevação de pressão.

Esta elevação do torque indica que não está havendo escorregamento do material prensado. As figuras 14 e 15 apresentam os gráficos destas duas variáveis. 


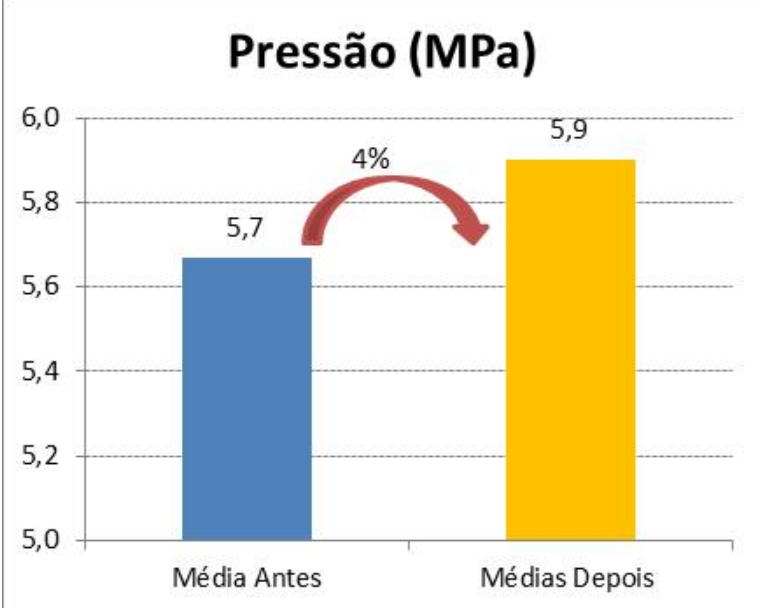

Figura 14. Pressão Hidráulica

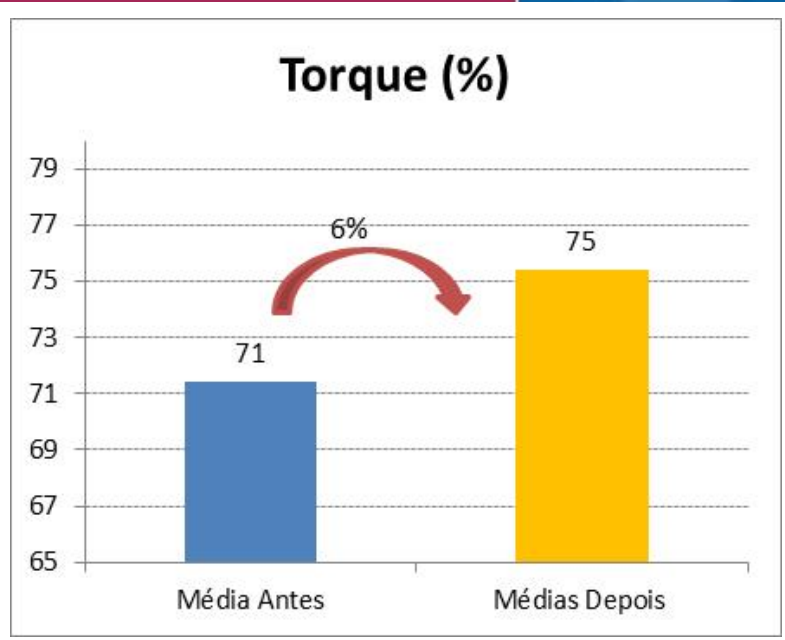

Figura 15. Torque

\subsection{Superfície Específica e Consumo de Energia}

Conforme já mencionado, o objetivo principal da prensa de rolos no processo de pelotização é a elevação da superfície específica $\left(\mathrm{cm}^{2} / \mathrm{g}\right)$, a figura 16 mostra o comportamento de ganho de $6 \%$ na superfície específica gerada pela prensa depois da aplicação da resina.

O fato da prensa estar realizando mais trabalho gerando maior superfície específica após a aplicação da resina, leva também a uma elevação no consumo de energia elétrica, esperava-se que este aumento de consumo fosse proporcional a elevação do ganho de superfície específica, no entanto os resultados apresentados na figura 17 mostraram uma elevação maior no consumo em relação a ganho de superfície.

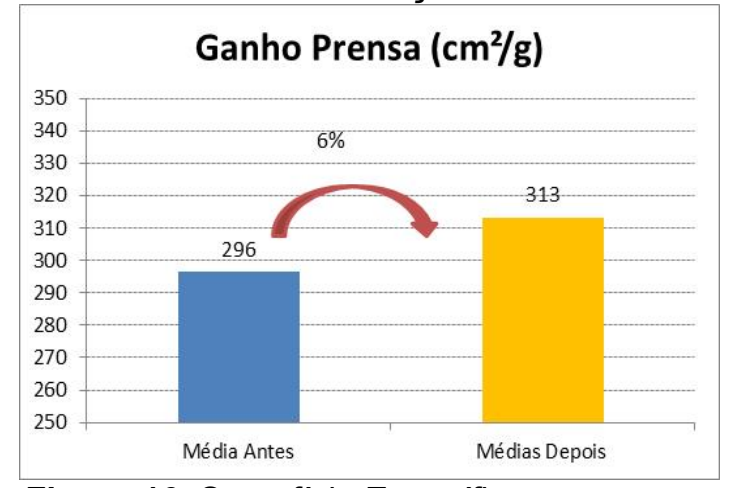

Figura 16. Superfície Especifica

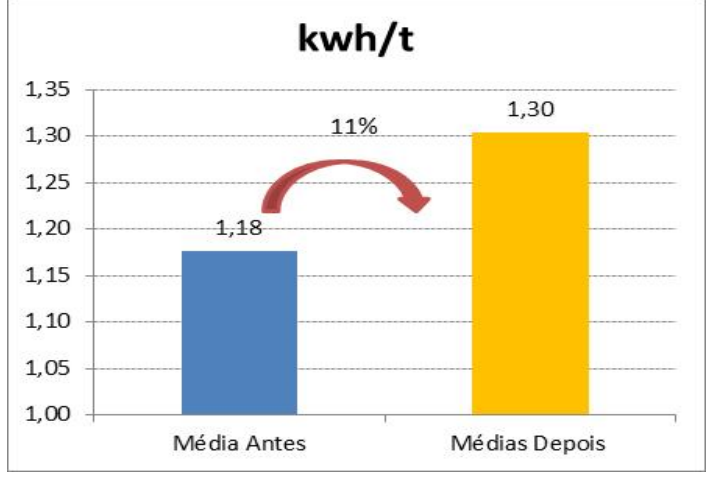

Figura 17. Consumo Específico de Energia

\subsection{Eficiência de Prensagem e Influência do Minério}

Uma forma de comparar as informações de ganho de superfície específica com a elevação do consumo específico de energia pode ser realizado através de uma análise de quanto a prensa está elevando a superfície específica $\left(\mathrm{cm}^{2} / \mathrm{g}\right)$ do minério para cada kwh/t de energia consumida, neste trabalho denominamos esta relação de Eficiência de Prensagem expresso em $\mathrm{cm}^{2} / \mathrm{g}$ por kwh/t.

A figura 18 abaixo apresenta como foi o comportamento da eficiência da prensa quando foi realizada a aplicação da resina.

Em uma primeira análise, verificamos que houve uma perda de eficiência da prensa depois da aplicação da resina, porém os estudos foram aprofundados para verificar a possibilidade de uma interferência externa nos resultados. 
É conhecido que dentre os minérios que utilizamos nas usinas de pelotização em Tubarão, o minério proveniente das minas de Itabira se destacam pela dificuldade de geração de superfície específica, de posse desta informação foi realizado um levantamento da participação deste minério no período de avaliação já mencionado. Observamos uma elevação substancial na participação deste minério após a aplicação da resina mostrado na figura 19.

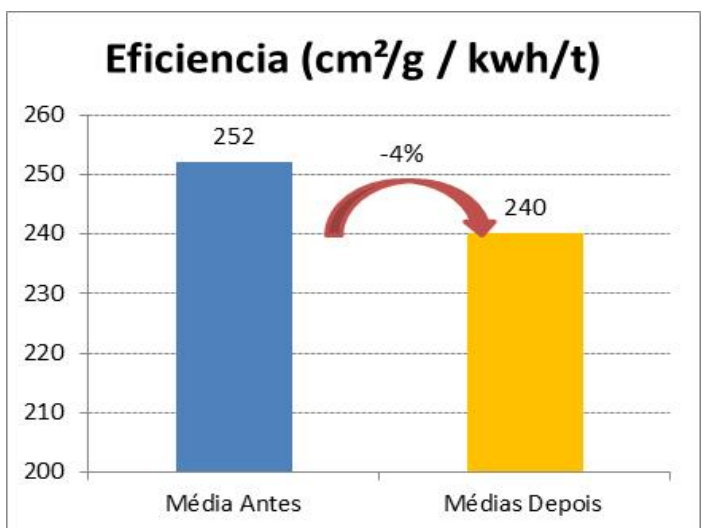

Figura 18. Eficiência de Prensagem

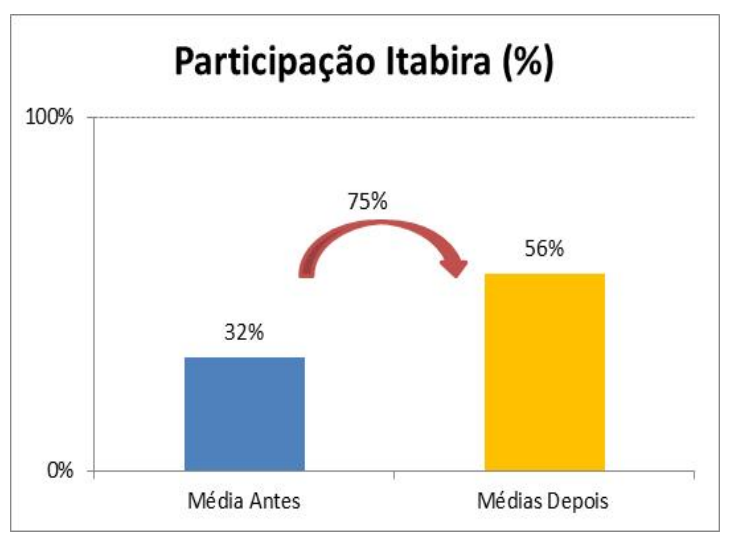

Figura 19. Participação do Minério de Itabira

Conforme apresentado, podemos verificar que a maior participação do minério de Itabira foi o responsável pela elevação do consumo específico de energia, o que impactou na perda de eficiência da prensa. Esta afirmação foi comprovada através dos resultados de eficiência de prensagem obtidos posteriormente ao período analisado, onde, ao retornar a participação do minério de Itabira aos patamares padrões, houve uma elevação na eficiência de prensagem, superior ao período anterior ao da aplicação da resina, como demonstrado nas figuras 20 e 21.

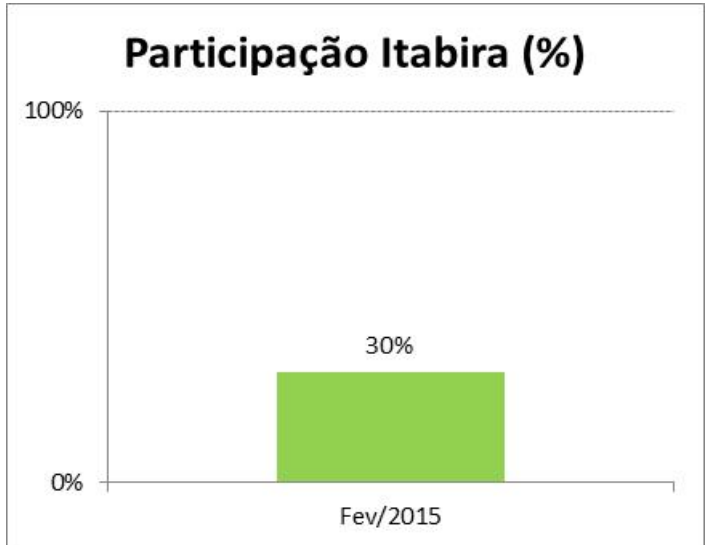

Figura 20. Participação do Minério de Itabira

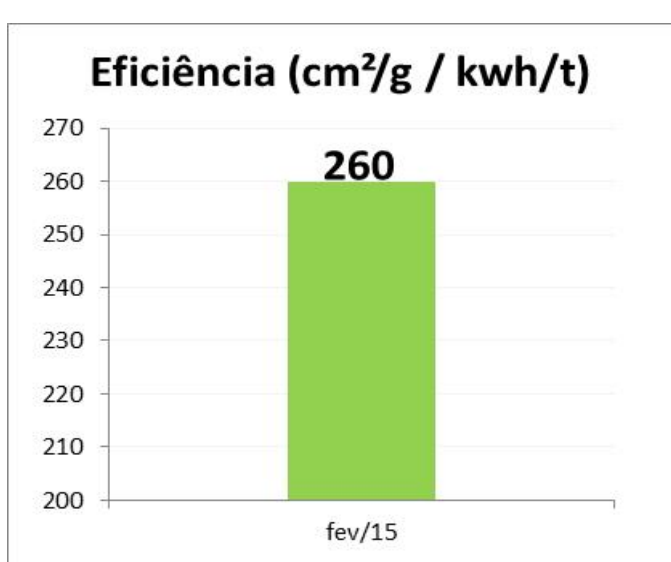

Figura 21. Eficiência de Prensagem

Este novo valor representa um acréscimo de 3,2\% na eficiência quando comparado ao período anterior à aplicação da resina.

\section{CONCLUSÃO}

As inspeções realizadas mostram que o problema de desgaste da bandagem dos rolos e desprendimento dos pinos foram controlados e a resina cerâmica está resistindo a aplicação tanto em relação ao desgaste, compressão e aderência na superfície do rolo, podendo assim prolongar a vida útil dos rolos. 
Em relação ao processo, os dados coletados nos indicam que não houve prejuízo a performance da prensa com a aplicação da resina cerâmica;

Foi observado uma elevação no ganho de superfície específica de $6 \%$ e $3,2 \%$ de aumento de eficiência na prensa;

Pôde-se notar que a maior participação do minério de Itabira influencia negativamente a performance da prensa;

A textura rugosa da resina cerâmica pode ter contribuído para que não houvesse perda de performance da prensa por escorregamento;

Devido a recente aplicação da resina (outubro/2014), neste trabalho não foi possível calcular a durabilidade da resina.

\section{Agradecimentos}

Este trabalho foi fruto do empenho de uma equipe multidisciplinar, e gostaríamos de deixar registrados nossos agradecimentos às equipes de: manutenção mecânica, manutenção elétrica, operação, instrumentação, automação e processo pela dedicação e esforço para concretização deste trabalho.

\section{BIBLIOGRAFIA}

1 Ribeiro FS, Cabello JF, Costa T. Aplicação de prensa de rolos em minério de ferro. REM: R. Esc. Minas, Ouro Preto. 2010;62(2):399-404.

2 Dantas L, Silva B, Subtil R, Freitas R, Moura R, Mayerhofer F. Aumento da eficiência de uma prensa de rolos de alta pressão aplicada a usina de pelotização da Vale. Vale. 2014:1-12.

3 Technical Machinery Documentation. KHD Humboldt Wedag AG. 1995.

4 Primeira escolha para tecnologia e serviços com prensa de rolos de alta pressão (HPGR). Catálogo Weir Minerals / KHD Humboldt Wedag. 2010:1-29.

5 Klymowsky R, Odenwald B. POLYCOM Scale-Up. Polysius. 2006:1-25.

6 Prensa de rolos de alta pressão para minério de ferro. Treinamento interno Vale. 2008:1-68.

7 Technical Datasheet ARC MX1, Chesterton, 2014. 